DOI: https://doi.org/10.36502/2020/droa.6171

\title{
Safety of Metformin in Hospitalized Patients with COVID-19
}

\author{
Mikhail $\mathrm{N}^{1^{*}}$, Wali $\mathrm{S}^{1}$ \\ ${ }^{1}$ Endocrinology Division, Department of Medicine, Olive-View-UCLA Medical Center, David-Geffen School of Medicine, CA, USA
}

Corresponding Author: Nasser Mikhail, MD ${ }^{\text {ORCID ID }}$

Address: Endocrinology Division, Department of Medicine, Olive-View-UCLA Medical Center, David-Geffen School of Medicine, CA, USA; E-mail: nmikhail@dhs.lacounty.gov

Received date: 10 September 2020; Accepted date: 03 October 2020; Published date: 10 October 2020

Citation: Mikhail N, Wali S. Safety of Metformin in Hospitalized Patients with COVID-19. Diab Res Open Access. 2020 Oct 10;2(3):68-71.

Copyright (C) 2020 Mikhail N, Wali S. This is an open-access article distributed under the Creative Commons Attribution License, which permits unrestricted use, distribution, and reproduction in any medium, provided the original work is properly cited.

\begin{abstract}
Background: It is unclear whether metformin should be continued or discontinued in patients with coronavirus disease 2019 (COVID-19) admitted to the hospital.

Objective: To review metformin safety, particularly its impact on mortality among hospitalized patients with COVID-19.

Methods: Review of English literature by PUBMED search until September 11, 2020. Search terms included diabetes, COVID-19, metformin, Retrospective studies, meta-analyses, pertinent reviews, pre-print articles, and consensus guidelines are reviewed.

Results: Retrospective studies suggest that metformin use prior to hospital admission may be associated with decreased mortality in patients with diabetes admitted to the hospital with COVID-19. Continuing metformin use after hospital admission did not have a significant impact on 28-day all-cause mortality. Metformin use after hospitalization of patients with COVID-19 was associated with approximately 4.6 times increase risk of lactic acidosis in patients with severe symptoms of COVID-19, patients taking $2 \mathrm{gm} / \mathrm{d}$ of metformin or higher, and patients with estimated glomerular filtration rate (eGFR) less than $60 \mathrm{ml} / \mathrm{min} / 1.73 \mathrm{~kg} / \mathrm{m}^{2}$. Metformin use in the hospital was associated with a significant decrease in the risk of heart failure and acute respiratory distress syndrome (ARDS).
\end{abstract}

Conclusions: In patients with diabetes and COVID-19 admitted to the hospital, metformin should not be used in presence of severe symptoms of COVID-19, kidney dysfunction (eGFR $<60 \mathrm{ml} / \mathrm{min} / 1.73 \mathrm{~m}^{2}$ ), and with daily doses of $2 \mathrm{gm}$ or more due to increased risk of lactic acidosis.

\section{Keywords}

COVID-19, Diabetes, Metformin, Safety, Mortality, Lactic Acidosis

\section{Introduction}

The prevalence of diabetes in COVID-19 patients ranges from $5 \cdot 3 \%$ to $58 \%$ representing the second comorbidity after hypertension [1,2]. Available data suggest that diabetes confers a poor prognosis in COVID-19 patients admitted to the hospital. In a meta- analysis of 30 retrospective studies $\left(n=6,45^{2}\right)$, Huang et al [3] showed that diabetes was associated with excess mortality: risk ratio (RR) 2.12 (95\% CI 1.443.03, $\mathrm{P}<0.001$, severe degree of COVID-19: RR 2.45, 95\% CI, 1.79-3.35, P < 0.001, ARDS: RR 4.64, 95\% CI, 1.86-11.58, $\mathrm{P}<\mathrm{0.001}$, and disease progression: RR 3.31, 
95\% CI, 1.08-10.14, $\mathrm{P}=$ 0.04. Hence, adequate glycemic control is necessary after patient admission. Metformin is the most common anti-diabetic drug worldwide due to its well-established long-term overall high efficacy and safety profile and low cost [4]. It is still unclear whether to continue or stop metformin after the admission of patients with COVID-19. The American Diabetes Association (ADA) generally recommends stopping all oral antidiabetic agents in most patients after hospital admission admitted to the hospital due to due to lack of data, presence of adverse effects, and limited efficacy [5]. The ADA recommends insulin as the standard therapy for hyperglycemia in the hospital [5]. However, one possible exception is metformin due to emerging data showing some benefits of this drug in patients hospitalized with COVID-19. This review discusses the safety profile of metformin in COVID-19 in the hospital setting, with special emphasis on its impact on mortality.

\section{Effect of Metformin on Mortality in} Hospitalized Patients with COVID-19

Effect of Pre-Admission Use of Metformin on Mortality:

The most comprehensive data in this respect may be derived from the recent meta-analysis conducted by Kow and Hassan [6]. In this study, the authors analyzed data (up to August 8, 2020) of 5 studies including 8,121 patients with diabetes and COVID-19 who were using metformin prior to hospital admission. Their pooled analysis revealed a significantly reduced risk for mortality with the use of metformin prior to admission, pooled odds ratio (OR) being 0.62 (95\% CI, o.43-0.89) compared to patients with diabetes who were non-users of metformin [6]. Interestingly, the largest study included in this metaanalysis by Bramante et al [7] that contributed to $48.7 \%$ of the meta-analysis weight showed that preadmission metformin use was associated with decreased in-hospital mortality in women only, OR 0.79 (95\% CI 0.64-0.98), but not in men. It should be emphasized that while the results of this meta-analysis are encouraging, they should be considered preliminary due to the following limitations. First, all included studies were retrospective prone for confounding factors. Second, it was not possible to know to what extent patients were adherent to metformin intake prior to hospital admission. Third, the duration and dosage of metformin were not known. Fourth, it was not clear in any of these studies whether patients continued to take metformin or discontinued it after admission to the hospital.

\section{Effect of Continuing Metformin Intake during Hospitalization:}

To the best of authors' knowledge, there is only one study that evaluated the effects of continuing metformin after admission on mortality in patients with diabetes and COVID-19 [8]. Thus, in this large $(n=1,213)$ retrospective study from China, Cheng et al [8] have shown that metformin use while in the hospital was not associated with an increase in 28-day all-cause mortality compared with metformin nonusers; adjusted hazard ratio (HR) $0.87,95 \%$ CI o.362.12); $\mathrm{P}=0.75$. These data, although based on $\mathrm{a}$ retrospective study, are reassuring.

\section{Adverse Effects of Metformin Use during Hospitalization of Patients with COVID-19 Effect of Metformin on Lactic Acidosis:}

Lactic acidosis is a rare, but potentially lethal adverse effect of metformin [9]. The large study of Cheng et al [8] allowed the evaluation of metformin safety in different subgroups of patients. Thus, they found that lactic acidosis was increased in patients with COVID-19 compared with metformin non-users, adjusted HR 4.66, 95\% 1.45-14.99; $\mathrm{P}=0.01$ [8]. However, this increased risk of lactic acidosis was limited to the following subgroups of patients: those with severe COVID-19, patients using metformin in doses of $2 \mathrm{gm} / \mathrm{d}$ or higher, and in presence of kidney dysfunction defined as eGFR $<60 \mathrm{ml} / \mathrm{min} / 1.73 \mathrm{~kg} / \mathrm{m}^{2}$ [8].

Effect of Metformin on Heart Failure and Acute Respiratory Distress Syndrome:

In the study of Cheng et al [8], metformin inhospital use was shown to be associated with decreased risk of heart failure adjusted HR o.61 (95\% CI 0.43-0.87; $\mathrm{P}=0.006$ ), and ARDS, adjusted HR 0.66, 95\% CI 0.46-0.96; $\mathrm{P}=0.03)$. There was no significant effect of metformin on acute kidney injury or disseminated intravascular coagulation. 


\section{Potential Mechanisms Underlying Metformin Clinical Benefits:}

Metformin has been shown to improve the immune response and reduce inflammation [10]. It should be emphasized that metformin should not be used in presence of hypoxia, decreased tissue perfusion, sepsis, acute or chronic kidney disease, and acute heart and liver failure to avoid the risk of lactic acidosis. Indeed, Cheng et al [8] found that serum levels of proinflammatory cytokines known to mediate cytokine storm in COVID-19 were increased to a lesser extent among metformin-users versus metformin non-users. Such pro-inflammatory cytokines included: interleukin-6, interleukin-2, and tumor necrosis-alpha (TNF- $\alpha$ ) [8]. Likewise, Chen et al [11] found that levels of IL- 6 were lower in metformin users than non-users.

Moreover, Chen et al [8] recorded lower neutrophil count among metformin users compared with nonusers.

\section{Conclusions and Future Needs}

Preliminary data suggest that metformin use prior to the hospitalization of patients with diabetes and COVID-19 might reduce mortality. Meanwhile, continuing metformin after hospitalization did not affect mortality, but increased the risk of lactic acidosis. The risk of lactic acidosis was evident only in patients with severe symptoms of COVID-19, those with kidney dysfunction, and in patients taking $2 \mathrm{~g}$ of metformin or more daily. Accordingly, metformin should be discontinued in cases of severe COVID-19 and kidney disease, and its daily doses should not exceed $2 \mathrm{~g}$. On the other hand, metformin in lower doses may be continued in mild cases, and in presence of normal kidney function in view of its possible benefits in reducing risk of heart failure and ARDS. Unfortunately, all current data related to COVID-19 and metformin are based on retrospective studies prone for multiple bias and confounding factors. Randomized trials are urgently needed to determine safety and efficacy of metformin in hospitalized COVID-19 patients.

\section{Financial Support}

None of the authors listed for this publication have any financial support.

\section{Conflict of Interest}

All authors have read and approved the final version of the manuscript. The authors have no conflicts of interest to declare.

\section{References}

[1] Singh AK, Gupta R, Ghosh A, Misra A. Diabetes in COVID-19: Prevalence, pathophysiology, prognosis and practical considerations. Diabetes Metab Syndr. 2020 Jul-Aug;14(4):303-10. [PMID: 32298981]

[2] Guan WJ, Ni ZY, Hu Y, Liang WH, Ou CQ, He JX, Liu L, Shan H, Lei CL, Hui DSC, Du B, Li LJ, Zeng G, Yuen KY, Chen RC, Tang CL, Wang T, Chen PY, Xiang J, Li SY, Wang JL, Liang ZJ, Peng YX, Wei L, Liu Y, Hu YH, Peng P, Wang JM, Liu JY, Chen Z, Li G, Zheng ZJ, Qiu SQ, Luo J, Ye CJ, Zhu SY, Zhong NS; China Medical Treatment Expert Group for Covid-19. Clinical Characteristics of Coronavirus Disease 2019 in China. N Engl J Med. 2020 Apr 30;382(18):1708-20. [PMID: 32109013]

[3] Huang I, Lim MA, Pranata R. Diabetes mellitus is associated with increased mortality and severity of disease in COVID-19 pneumonia - A systematic review, meta-analysis, and meta-regression. Diabetes Metab Syndr. 2020 Jul-Aug;14(4):395-403. [PMID: 32334395]

[4] American Diabetes Association. 9. Pharmacologic Approaches to Glycemic Treatment: Standards of Medical Care in Diabetes-2020. Diabetes Care. 2020 Jan;43(Suppl 1):S98-10. [PMID: 31862752]

[5] American Diabetes Association. 15. Diabetes Care in the Hospital: Standards of Medical Care in Diabetes2020. Diabetes Care. 2020 Jan;43(Suppl 1):S193-202. [PMID: 31862758]

[6] Kow CS, Hasan SS. Mortality of COVID-19 with preadmission metformin use in patients with diabetes: a meta-analysis. J Med Virol. 2020 Sep 9. [PMID: 32902868]

[7] Bramante C, Ingraham N, Murray T, Marmor S, Hoversten S, Gronski J, McNeil C, Feng R, Guzman G, Abdelwahab N, King S, Meehan T, Benson B, Pendleton K, Vojta D, Tignanelli CJ. Observational Study of Metformin and Risk of Mortality in Patients Hospitalized with Covid-19. medRxiv [Preprint]. 2020 Jun 28:2020.06.19.20135095. [PMID: 32607520]

[8] Cheng X, Liu YM, Li H, Zhang X, Lei F, Qin JJ, Chen Z, Deng KQ, Lin L, Chen MM, Song X, Xia M, Huang X, 

Oct 10;2(3):68-71.

\section{Original Article}

Liu W, Cai J, Zhang XJ, Zhou F, Zhang P, Wang Y, Ma X, Xu Q, Yang J, Ye P, Mao W, Huang X, Xia J, Zhang BH, Guo J, Zhu L, Lu Z, Yuan Y, Wei X, She ZG, Ji YX, Li H. Metformin Is Associated with Higher Incidence of Acidosis, but Not Mortality, in Individuals with COVID19 and Pre-existing Type 2 Diabetes. Cell Metab. 2020 Aug 20:S1550-4131(20)30426-35. [PMID: 32861268] [9] DeFronzo R, Fleming GA, Chen K, Bicsak TA. Metformin-associated lactic acidosis: Current perspectives on causes and risk. Metabolism. 2016 Feb;65(2):20-29. [PMID: 26773926]
[10] Cameron AR, Morrison VL, Levin D, Mohan M, Forteath C, Beall C, McNeilly AD, Balfour DJ, Savinko T, Wong AK, Viollet B, Sakamoto K, Fagerholm SC, Foretz M, Lang CC, Rena G. Anti-Inflammatory Effects of Metformin Irrespective of Diabetes Status. Circ Res. 2016 Aug 19;119(5):652-65. [PMID: 27418629]

[11] Chen Y, Yang D, Cheng B, Chen J, Peng A, Yang C, Liu C, Xiong M, Deng A, Zhang Y, Zheng L, Huang K. Clinical Characteristics and Outcomes of Patients With Diabetes and COVID-19 in Association With Glucose-Lowering Medication. Diabetes Care. 2020 Jul;43(7):1399-407. [PMID: 32409498] 